\title{
Padrão de mobilidade do caso colombiano do final do século XX e começos do século XXI. Uma aproximação a partir dos censos de 1993 e 2005 e do sistema de registro sobre deslocamento forçado.
}

\author{
Sulma Marcela Cuervo Ramírez $z^{1}$ \\ Alisson Flávio Barbieri \\ Jose Irineu Rangel Rigotti ${ }^{3}$
}

\begin{abstract}
Resumo
O comportamento da migração interna, como parte das transformações econômicas, produtivas e sociais que a Colombia experimentou desde meados do século XX e na primeira década do século atual, sob o marco econômico da globalização e do neoliberalismo, encontra-se configurado em situações de conflito político e armado. Evidencias empíricas sobre o tamanho, a intensidade, a direção e a natureza das causas dos fluxos migratórios, que possibilitam os Censos demográficos na Colômbia, sugerem que de fato existe um padrão de migração específico para o caso colombiano, mas no qual o comportamento dos movimentos forçados, derivados do conflito, parecem dissolver-se. Estes, ou são percebidos, de forma geral como "migrações voluntárias", ou, simplesmente não são contabilizados porque escapam ao escopo conceitual e espacial das fontes censitárias. O propósito deste artigo é contribuir na compreensão do comportamento das migrações da Colômbia, na transição ao século XXI, integrando na sua análise outras formas de mobilidade interna e internacional de caráter voluntário e forçado. Pretende-se resgatar a importância da complementariedade das fontes de informação para alcançar uma maior compreensão do conceito de mobilidade espacial, e dimensionar, no caso da Colômbia, o impacto do conflito armado além das fronteiras nacionais. Para alcançar este propósito, foram analisados os dados sobre migrações internas voluntárias e forçadas que fornecem os censos demográficos de 1993 e de 2005; as informações sobre deslocamentos forçados, para o período de 1980 a 2014, proporcionados pelo Sistema Único de Registro de Deslocados Forçados; as estimações de migração internacional do DANE; e as informações sobre refugiados internacionais divulgadas pela ACNUR $^{4}$. Os resultados da análise fornecem elementos para confirmar que o padrão migratório colombiano não pode ser interpretado sem considerar outras formas de mobilidade.
\end{abstract}

Palavras chave: migração interna, deslocamento forçado, refugiados internacionais, migração internacional, história econômica, conflito armado.

\footnotetext{
1 Pós Doutorado Programa de Pós-Graduação em Demografia, Universidade Federal de Minas Gerais.

${ }^{2}$ Professor Associado e Pesquisador Departamento de Demografia, Universidade Federal de Minas Gerais.

${ }^{3}$ Professor Associado e Pesquisador Departamento de Demografia, Universidade Federal de Minas Gerais.

${ }^{4} \mathrm{O}$ trabalho avança sobre os resultados da Tese de Doutorado em Demografia: Migração interna e deslocamento forçado: Análise do padrão migratório colombiano do final do século XX e começo do século XXI (2014).
} 


\section{Introdução}

Na revisão da literatura recente, os trabalhos coincidem em que o fenômeno migratório do final do século passado e deste novo século é, ante tudo, um fenômeno global (Castles, 1993; Massey, 1993, 1996; Massey \& Taylor, 2004; Wihtol de Wenden, 2013). No entanto, os cientistas sociais que analisam as causas e consequências da migração, não somente se centram na migração internacional, assumem que as migrações internas se esgotaram e excluem as migrações forçadas. Com algumas exceções, por exemplo, Castles (1993), poucas vezes é salientado que as distintas formas e tipologias de migração fazem parte de um mesmo processo, e que, em condições ideais, deveriam ser estudadas de maneira conjunta. Os acadêmicos tratam as três formas de migração como se fossem processos fundamentalmente diferentes (Zolberg et al., 1989).

A teoria dos sistemas mundiais, inspirada em Wallesterin e apurada por Massey, et al. (1996) fornece elementos que podem ajudar compreender, não apenas as conexões possíveis entre as migrações internas e internacionais, mas as conexões entre migrações de caráter voluntário e forçado. Sustentada na corrente teórica estruturalista, esta teoria explica que as migrações são o resultado dos desequilíbrios que envolveram o processo de penetração do sistema capitalista nos países em vias de desenvolvimento, decorrente da estrutura do mercado laboral mundial, que se desenvolve e expande desde o século XVI (Massey, 1993).

Os métodos de penetração do sistema de acumulação de capital significariam a consolidação da posse das terras para garantir a mecanização agrícola e a introdução de cultivos rentáveis, se necessário, através de métodos violentos. Nesse processo torna-se inevitável a destruição dos sistemas tradicionais, tanto de posse de terra, quanto de produção agrícola e pecuária; e a criação de trabalhadores "desnecessários", os que uma vez deslocados encontram na migração para as periferias dos centros urbanos ou para outros países uma alternativa de sobrevivência (Massey, 1989, 1993). Sob este arcabouço teórico é possível vislumbrar que as migrações internas não podem ser fragmentadas, mas que elas abrangem também os deslocamentos forçados, os quais respondem em maior medida a questões políticas e a conflitos ao interior dos territórios nacionais.

Frente ao marco da globalização e da neoliberalização, o qual confirma uma maior interconexão global entre os países, os mercados, os capitais e as pessoas, dentro e fora dos territórios nacionais, é plausível esperar que as diversas formas de mobilidade revelem essas interconexões. Isto supõe, de uma parte, que os que se conhecem como deslocamentos forçados não estão desligados das migrações, percebidas como voluntárias, mas que fazem parte de um mesmo processo; e de outra, que em alguma medida, os espaços locais, onde tem lugar os movimentos espaciais dos indivíduos, receberam os impactos das economias rentáveis, sejam elas reconhecidas como lícitas ou ilícitas. 
No caso da Colômbia, onde as condições econômicas estruturais não são as mais competitivas para garantir uma justa concorrência dos mercados, frente a outros países desenvolvidos, a combinação da globalização e neoliberalismo acentuaram as condições de desigualdade internas, e com elas, a reprodução de padrões de mobilidade particulares. Enquanto o Estado historicamente não conseguiu consolidar-se em todo o território nacional, amplos espaços em áreas de fronteiras internas e interacionais se configuraram para o surgimento de setores de produção ilícitos que garantiram uma ampla acumulação de capital por parte de grupos à margem da lei. A fragilidade institucional favoreceria também o nascimento de grupos de insurgência e de forças paraestatais que acabaram se disputando esses territórios e as suas populações. A magnitude que alcançaram as atividades ilegais fortaleceriam esses grupos em armamento e poder do qual só poderia resultar um complexo conflito armado que se prolongou no tempo e que já supera cinco décadas.

No entanto, ainda que este fenômeno tenha sido amplamente analisado, são poucos os estudos que integram na sua análise empírica tanto as dinâmicas de migração interna quanto da migração internacional, seja em condição voluntária ou forçada. Esta falência, que se reconhece para o caso colombiano, também é sinalada para outras latitudes por autores como Castles (2004), Zolberg (1989) de Haas (2006; 2010). A fim de contribuir na compreensão dos processos migratórios da Colômbia, como parte do processo de transformação econômica e política que o país experimentou na transição ao século XXI, neste artigo se fornece essencialmente uma aproximação ao padrão de mobilidade colombiano, o qual integra como balanço geral o volume e tendência das migrações internas e internacionais de caráter "voluntário" e forçado, para os períodos de 1988 a 1993 e de 2000 a 2005.

\section{Materiais e métodos}

O estudo sobre as migrações internas se sustenta na análise dos microdados censitários demográficos referentes a 1993 e 2005, fornecidos pelo Departamento Administrativo Nacional de Estatística - DANE. O conceito de migrante refere-se à pessoa que residia, cinco anos atrás, em um município diferente do município de recenseamento, independente de seu local de nascimento, e que sobreviveu à mortalidade e a reemigração.

Graças a que no formulário censitário do Censo 2005 foram incorporadas perguntas sobre as causas da migração, foi possível identificar migrantes forçados internos. Estes correspondem aos migrantes que escolheram, entre várias opções de resposta, aquela que especifica como causa principal: "amenaza o riesgo para su vida, su libertad o su integridad física ocasionada por la violência”. Por razões operacionais e para facilitar a diferenciação frente aos migrantes forçados, os migrantes que escolheram qualquer uma das restantes opções de resposta foram considerados como "migrantes voluntários". Cabe dizer que esta classificação se reconhece arbitrária. De fato, entre as opções de resposta não se inclui alguma que sugira 
uma escolha livre de dificuldade. De modo que os movimentos implicitamente envolvem algum grau forçoso.

No caso do deslocamento forçado, foram analisados os dados coletados mediante o Sistema de Registro Único de População Deslocada da Rede Nacional de Informação sobre as Vítimas do Conflito Armado - RUPD-RNI, da Colômbia, disponível para o período 19852014. A lei 1448 de 2011 define a vitima de deslocamento forçado como "toda persona que se ha visto obligada a migrar dentro del territorio nacional abandonando su localidad de residencia o actividades económicas habituales, porque su vida, su integridad física, su seguridad o su libertad personal han sido vulneradas o se encuentran directamente amenazadas (...)”. Para este caso consideram-se os eventos acumulados anualmente, independentemente de se foram experimentados por uma mesma pessoa, ou se aconteceram dentro ou fora dos limites municipais.

Para dimensionar o volume das migrações internacionais "voluntárias" foram considerados os resultados do Censo 2005 referente à declaração dos domicílios sobre a existência de emigrantes internacionais, assim como as estimações de emigrantes internacionais realizados pelo DANE, a partir do sistema de registro de mobilidade internacional administrado pelo Departamento Administrativo de Segurança DAS.

A fim de dimensionar o volume e comportamento dos migrantes internacionais forçados foram observados os registros sobre refugiados internacionais da Agencia de Refugiados das Nações Unidas, disponíveis a partir de 1985.

A obtenção dos resultados integrou à aplicação das técnicas diretas de estimação da migração, tanto para a estimação das taxas de migração interna "voluntária e forçada" a partir dos Censos de 1993 e 2005, quanto de deslocamento forçado, a partir do Sistema Único de Registro de Deslocamento Foçado, da Rede Nacional de Atendimento paras Vitimas do Conflito Armado, para os períodos quinquenais 1988-1993 e 2000-2005.

\section{Considerações históricas para a compreensão do padrão de mobilidade colombiano}

Frente a outros países da região, como Argentina, Brasil e o México, a Colômbia foi um país que iniciou tardiamente seu processo de industrialização, apenas na terceira década do século, devido principalmente aos altos custos do transporte e à consequente dificuldade para integração dos mercados regionais e com o resto do mundo (Kalmanovitz, 2006; Villa \& Esguerra, 2007). As cidades que conseguiram instaurar a indústria consolidariam, desde a segunda metade do século $\mathrm{XX}$, os canais para a imigração e, consequentemente, para o processo de urbanização, fundamentalmente sobre a Região dos Andes. 
Mas, a industrialização não apenas começou tarde, mas se desmantelaria prematuramente. $\mathrm{O}$ processo conhecido como desindustrialização, no caso colombiano teria começado na década de 1980, e se agudizaria sobre a década de 1990, quando foram aplicadas as políticas de abertura econômica e quando o papel do Estado na economia, cederia seu caráter protecionista sobre os setores produtivos.

Os censos demográficos disponíveis mostram que praticamente durante todo o século XIX a taxa de crescimento demográfico se manteve próxima de $1,7 \%$ anual. Com essa taxa a população incrementou de 1.228 .000 mil habitantes em 1825 a 5.860 .000 habitantes em 1918. Só até a terceira década do século XX a taxa de crescimento se aproximou a $2 \%$ anual, favorecendo o aumento da população que, em 1938, atingiria 8.700.000 habitantes. A partir da década de 1950 o crescimento demográfico se intensifica. A população total cresce $3 \%$ anual e o número de habitantes passa de 11.5 milhões em 1953 a 17.5 milhões em 1964 . O crescimento é mais expressivo nas áreas urbanas, onde a população se incrementou de 4,5 milhões em 1951 a 9 milhões em 1964, com taxas próximas ao 4,5\% anual. Em menos de cinco décadas a população praticamente se quadruplicou. A participação porcentual da população rural, de $70 \%$ na década de 1930 , passa a ocupar apenas $30 \%$ ao final do século.

Nesta transição de redistribuição populacional as cidades capitais de departamento, particularmente aquelas que se consolidaram industrialmente, e seus municípios contíguos, denominados como Áreas Metropolitanas, cresceram aceleradamente e concentraram a população de maneira progressiva. Em 1951 estas abrigavam perto de $20 \%$ da população, enquanto $60 \%$ se distribuíam nos municípios menores de 50.000 habitantes (predominantemente rurais) e o $20 \%$ restante nas cidades médias, algumas das quais correspondem a capitais departamentais. Esta distribuição foi se transformando, de modo que, em $2005,70 \%$ da população estava concentrada entre as áreas metropolitanas e as cidades médias; e 30\% restante nos municípios com predominância rural.

No contexto da América Latina, a Colômbia foi um dos países que mais rápido começou a desconcentração da população das áreas rurais (Kalmanovitz \& López, 2006). De uma parte, isto foi favorecido pelo intenso crescimento demográfico nas áreas rurais nas décadas 1950 e 1960, quando o crescimento atingia perto de $4 \%$ anual, o qual pressionaria a saída de camponeses em procura de novas oportunidades. E de outra, por profundas problemáticas de caráter econômico e político, que derivaram em confrontos violentos causando o deslocamento forçoso de milhares de camponeses, favorecendo a sua concentração tanto nas áreas urbanas, para quando as taxas de crescimento urbano aproximavam-se de 6,5\% anuais, quanto em regiões de fronteira interna e internacional, principalmente em áreas de florestas tropicais. 
As problemáticas estruturais, que contextualizaram essas migrações massivas da década de 1950 não desapareceram. Diferentes autores concordam em que as desigualdades na repartição da terra, a estrutura fundiária, o centralismo econômico e as inequidades regionais, não apenas permanecem, mas explicam porque hoje se negocia um novo acordo de paz entre o Estado e o Grupo de Insurgência armada FARC na Habana Cuba (Palácios \& Safford, 2002; Fajardo, 2010, Robinson, 2010; Pécaut, 2013).

Os conflitos políticos acontecidos durante o século XIX, depois da guerra de independência, na sua maioria, foram derivados de disputas políticas entre os dois partidos políticos tradicionais, liberal e conservador, e envolveram praticamente todos os Departamentos do país $^{5}$ (Deas, 2000; Pardo, 2008). O conflito armado que atualmente se reconhece na Colômbia se originou paradoxalmente quando as lideranças dos partidos políticos tradicionais deixaram as rixas e formalizaram uma coalisão política, denominada como Frente Nacional (Palácios \& Safford, 2002; Pécaut, 2013). Período no qual surgiam as guerrilhas campesinas e as suas lutas revolucionárias para reivindicar os direitos dos camponeses, os quais tinham sido humilhados na guerra conhecida como La Violencia dos anos de 1950 (Bushnell, 2008; Palácios \& Safford, 2002; Pardo, 2008).

A luta das guerrilhas se fortaleceria inicialmente com as ideias da esquerda revolucionária florescentes na América Latina no período da Guerra Fria nos anos 70s, mas se corromperia depois do negócio do narcotráfico e do terrorismo, na década de 1980 (Palácios \& Sáfford, 2002; Pardo, 2008). Posteriormente, a incursão de outros atores conhecidos como paramilitares, que em principio surgiram para combater todo o que simbolizara "a revolução armada e não armada" ao final dos anos 1980, tornaram o conflito ainda mais complexo e de difícil resolução (Rondeiros, 2014). Na transição ao século XX o conflito armado atingiu níveis de enorme complexidade em todo o território nacional, que configuram não apenas a presencia de diferentes grupos armados, de distinta orientação política, incluídas as Forças Armadas, mas também seu envolvimento direto ou indireto com diversas formas de acumulação de capital, lícito e ilícito, como o narcotráfico.

Durante este mesmo período de transição surgiram polos de produção de riqueza nas áreas de baixa densidade, principalmente nas áreas de floresta tropical de colonização tardia, derivados da mineração do petróleo, a exploração do ouro, o produção do gado, o agronegócio de produtos como a palma africana e da droga, o que adicionalmente provocou a afluência de população, de capitais e de novos conflitos não controlados (Fajardo, 2010, Pécaut, 2013; González et al. 2002). Os grupos paramilitares, que em princípios seguiam os passos dos grupos guerrilheiros para conter as ideias revolucionárias e para defender os interesses de grupos económicos privados, agora disputariam com essas guerrilhas o domínio e controle dos territórios altamente lucrativos. A coexistência violenta dos grupos armados,

\footnotetext{
${ }^{5}$ Os Departamentos equivalem aos Estados Federais no Brasil.
} 
do acionar dos narcotraficantes para o controle espacial do mercado da droga, somada às ações da Polícia e das Forças Armadas, engendrariam a violência em praticamente todo o território nacional durante toda a década de 1990 e de 2000 (Rondeiros, 2014).

De forma que o conflito armado e de violência é o que configura o padrão migratório colombiano desde o final da década de 1980. Segundo estatísticas oficiais da Rede Nacional de Informação da Unidade para a Atenção e Reparação Integral às Vítimas, em 2014, o conflito decorreram em torno de 6,372,539 vítimas, das quais 5.535.883 seriam vitimas de deslocamento forçado, entre 1985 e 2014 (RNI, 2014). Como consequência do conflito, 400.000 pessoas a mais procuraram refúgio em outros países, segundo as estatísticas da ACNUR (2015), sem contar as migrações internas e internacionais relacionadas indiretamente com o conflito.

\section{As migrações voluntárias e forçadas no balanço migratório colombiano de final do século XX e começos do século XXI}

\subsection{As migrações internas}

Segundo os últimos censos na Colômbia, entre 1993 e 2005, a população cresceu apenas $1,3 \%$ ao ano. Isto significou um aumentou aproximado de seis milhões de habitantes. No entanto, o número de migrantes internos intermunicipais de data fixa passou de 4.161.864 entre 1988-1993 a 2.666.142 entre 2000-2005. No primeiro período, perto de $13 \%$ da população mudou de município de residência, enquanto apenas 6,5\% o fizeram entre 2000 e 2005. Uma queda de quase 6,5 pontos porcentuais, que supera amplamente as variações na participação da migração intermunicipal, frente ao total da população, que apresentaram boa parte dos países da América Latina para os mesmos períodos, nos quais a diminuição oscilou em mais ou menos 1,5\% (Busso \& Rodríguez, 2009).

Este declínio do volume de migrantes internos de data fixa na Colômbia, porém, não pode ser interpretado como uma simples diminuição do estoque de migrantes potenciais nas áreas rurais ao longo da primeira metade do século XX, em função das disparidades de absorção de mão de obra do mercado de trabalho e de diferenças salariais entre as áreas rural e urbana: como supõe o modelo de equilíbrio da teoria neoclássica, ou as restrições à competitividade impostas pelas economias centrais de ocidente, sob a perspectiva teórica estruturalista do modelo centro periferia.

A interpretação das informações sobre migração e deslocamento forçado que fornecem as fontes disponíveis devem levar em consideração vários aspectos concomitantes. A exacerbação do conflito armado, desde princípios da década de 1990 e durante toda a década de 2000, com seus impactos no comportamento do deslocamento forçado, pode ter afetado as 
tendências da migração interna de três formas diferentes. Em primeiro lugar, é plausível que naqueles municípios onde os deslocamentos forçados tenham acontecido dentro dos mesmos limites político-administrativos, geralmente desde as áreas rurais para os casos urbanos, a probabilidade à migração dos mesmos deslocados para outros municípios tenha-se visto diminuída, impactando negativamente a migração intermunicipal. Em segundo, a situação de crise política e de insegurança e medo em que se encontravam envolvidas as pessoas que tivessem efetuado movimentos migratórios intermunicipais em condição forçada, poderiam ter omitido informação na sua condição de migrantes, impactando assim a sua contabilização e, portanto, o volume da migração de forma geral.

Em terceiro lugar, de forma correspondente ao aprofundamento do conflito armado, este pode ter derivado no aumento de migrantes internacionais, de natureza voluntária e forçada, diminuindo assim o potencial de migrantes internos. E finalmente, é plausível que a acentuada diminuição do número de migrantes internos de data fixa entre os dois períodos da análise reflita, em alguma medida, uma perda de cobertura de migrantes internos que, paradoxalmente, o desenho metodológico do Censo 2005, itinerante por conglomerados de municípios, derivou, sob o motivo de garantir a maior cobertura da população em todo o território nacional.

As considerações anteriores sugerem que a interpretação do comportamento da migração interna de data fixa entre os dois períodos de análise não pode ser feita sem sopesar, paralelamente, o comportamento das outras formas de mobilidade que acabam integrando o padrão de mobilidade colombiano. Neste mesmo sentido, cabe advertir ao leitor que, para a análise e interpretação do padrão de mobilidade e suas variações nos períodos de análise, apresentado na tabela 1 , devem ser ponderados os seguintes aspectos:

a) O desenho metodológico do Censo 2005, que consistiu em coletar as informações de forma itinerante por conglomerados de municípios ao longo de um ano, restringe a estrita comparabilidade do volume de migração de data fixa frente ao Censo de 1993;

b) Os impactos do conflito armado sobre os migrantes, em termos do sentimento de insegurança, que pode ter afetado a autodeclararão afetando o volume no Censo 2005;

c) A impossibilidade de dimensionar o volume de migrantes forçados no total de migrantes internos no caso do Censo de 1993. 
Tabela 1. Primeiro cenário do Padrão de Mobilidade Colombiano quinquênio 1988-1993 e 2000-2005. Migrantes e Deslocados Internos de Data Fixa Intermunicipais, Deslocamentos Forçados Internos intra e intermunicipais, Migrantes Internacionais e Refugiados Internacionais, segundo escala e causa dos movimentos.

\begin{tabular}{|c|c|c|}
\hline Cáusa e escala espacial dos movimentos & $1988-1993$ & $2000-2005$ \\
\hline \multicolumn{3}{|l|}{ Movimentos Internos } \\
\hline Migrantes "Voluntários" de Data Fixa segundo Censo (1) & 4.161 .862 & 2.455 .473 \\
\hline Migrantes Forçados de Data Fixa segundo Censo (2) & $?$ & 210.669 \\
\hline $\begin{array}{l}\text { Deslocamentos Forçados segundo Registro Único de População Deslocada (3) } \\
\text { Movimentos Internacionais }\end{array}$ & 108.950 & 2.208 .920 \\
\hline Migrantes Internacionais (4) & 783.496 & 883.420 \\
\hline Refugiados internacionais (5) & 2.178 & 145.655 \\
\hline \multicolumn{3}{|c|}{$\begin{array}{l}\text { Fontes de informação: } \\
\text { (1) Censos de } 1993 \text { e de } 2005 \text { do DANE; } \\
\text { (2) Migrantes forçados de data fixa obtidos especificamente para o Censo } 2005 \text { DANE; } \\
\text { (3) Registro Único de População Deslocada (RUPD) da Rede Nacional de Informação RNI da Unidade de } \\
\text { Vítimas do Conflito Armado na Colômbia; } \\
\text { (4) Estimações migração internacional do DANE, } 2007 \\
\text { (5) Agência de Refugiados para as Nações Unidas - ACNUR }\end{array}$} \\
\hline
\end{tabular}

\subsection{As migrações internacionais}

Segundo os registros do DANE sobre colombianos residentes em outros países, na década de 1960 já se contabilizavam ao redor de 192 mil colombianos, em 1980 perto de 818 mil, em 1985 perto de 1,2 milhão e em 1993 perto de 2,3 milhões DANE (2007). O que sugere também que a consolidação dos fluxos de colombianos para outros países teria sido paralela ao processo de consolidação das trajetórias migratórias internas desde a segunda metade do século XX. A partir desses registros e dos microdados do Sistema de Informação de Movimentos Internacionais do Departamento Administrativo de Segurança - DAS, o DANE estimou a emigração internacional para períodos quinquenais desde 1970 até 2005, durante os quais teriam emigrado no total ao redor de quatro milhões de colombianos.

Os censos demográficos têm permitido verificar as variações do número de migrantes dentro do país, aquelas que hipoteticamente são produzidas de forma voluntária. Perante as dimensões da problemática do conflito armado e da necessidade de medir seu impacto, o DANE, no último Censo 2005, fez uma primeira tentativa para medir tanto a emigração forçada interna, quanto a emigração internacional. Para esta última incorporou perguntas sobre familiares no estrangeiro, formulada a todos os domicílios. No Censo 2005, em 296.063 domicílios os entrevistados declararam ter pelo menos um membro da família residindo em um país estrangeiro, o que no total corresponde a 460.232 emigrantes. Os resultados do Censo 2005 do DANE não coincidem nem com o que revelam outras fontes de dados nem com o que sugerem as estimativas de emigração internacional da mesma instituição. Deve ser considerado que grupos familiares completos puderam ter-se reunido nos destinos internacionais e, consequentemente, não foram captados no censo. Os 
resultados censitários, porém, fornecem pistas acerca das suas tendências e sobre a estrutura espacial de origens e destinos, de absoluta relevância frente aos objetivos deste estudo e sobre os quais se pretende aprofundar em estudos futuros. A distribuição destes emigrantes em diferentes períodos do tempo pode ser apreciada na tabela 2.

Tabela 2 Distribuição dos emigrantes internacionais de origem colombiano segundo país de destino e período da emigração

\begin{tabular}{|c|c|c|c|c|c|c|c|c|}
\hline & $\begin{array}{c}\text { Antes de } \\
1996\end{array}$ & $\%$ & $1996-2000$ & $\%$ & $2001-2005$ & $\%$ & Total & $\%$ \\
\hline Venezuela & 40.192 & 31,5 & 15.100 & 12,5 & 36.796 & 17,3 & 92.132 & 20,0 \\
\hline Equador & 2.543 & 2,0 & 2.331 & 1,9 & 9.236 & 4,4 & 14.114 & 3,1 \\
\hline Panamá & 1142 & 0,9 & 1136 & 0,9 & 4135 & 1,9 & 6.415 & 1,4 \\
\hline Costa Rica & 592 & 0,5 & 1.131 & 0,9 & 3.560 & 1,7 & 5.284 & 1,1 \\
\hline México & 1.115 & 0,9 & 1.166 & 1,0 & 2.788 & 1,3 & 5.071 & 1,1 \\
\hline Perú & 273 & 0,2 & 233 & 0,2 & 889 & 0,4 & 1.395 & 0,3 \\
\hline Bolívia & 139 & 0,1 & 114 & 0,1 & 395 & 0,2 & 648 & 0,1 \\
\hline USA & 55.363 & 43,5 & 46.565 & 38,6 & 57.184 & 27,0 & 159.194 & 34,6 \\
\hline Espanha & 9.662 & 7,6 & 34.690 & 28,8 & 61.653 & 29,1 & 106.041 & 23,0 \\
\hline Canadá & 1.687 & 1,3 & 2.568 & 2,1 & 5.853 & 2,8 & 10.111 & 2,2 \\
\hline Austrália & 525 & 0,4 & 529 & 0,4 & 1.229 & 0,6 & 2.284 & 0,5 \\
\hline \multirow[t]{2}{*}{ Otros } & 14.182 & 11,1 & 15.077 & 12,5 & 28.459 & 13,4 & 57.742 & 12,5 \\
\hline & 127.415 & 100 & 120.640 & 100 & 212.177 & 100 & 460.432 & 100 \\
\hline
\end{tabular}

Fonte: Censo 2005. Elaboração própria.

Os resultados censitários mostram claramente que em todos os períodos o principal destino foi Estados Unidos. A Venezuela diminui a captação de colombianos, enquanto a Espanha a aumentou. Embora em menor proporção, os países fronteiriços de Equador e Panamá, vêm aumentando a participação como principais destinos.

\subsection{As migrações forçadas e os deslocamentos forçados}

No censo 2005 foram detectados 210.669 migrantes que mudaram de residência porque sua vida tinha sido ameaçada e corria perigo. Isto corresponde a $8 \%$ do total dos migrantes internos de data fixa. As fontes de informação no país dedicadas à medição do deslocamento forçado, que levam registros desde a década de 1980 mediante o Registro Único de População Deslocada, administrada atualmente pela Rede Nacional de Informação da Unidade de Vítimas - RNI indica, porém, que o número total de deslocados, apenas em 2000, foi de 415.354 pessoas, praticamente o dobro do registrado pelo censo em um quinquênio. Segundo esta fonte, no quinquênio 1988-1993, foram deslocadas em torno de 98.245 pessoas; e no quinquênio 2000-2005, em torno de 2.249.955 pessoas.

A marcante diferença do volume de deslocamentos no último quinquênio entre as duas fontes de informação, o Censo 2005 e o RUPD-RNI, obedece fundamentalmente a que são dois eventos de naturezas diferentes. Levando em consideração a escala espacial, primeiro, o deslocado forçado não precisa sair de um mesmo município para ser considerado como deslocado. Muitos dos eventos forçados acontecem dentro do mesmo município, desde as áreas rurais para as respectivas "cabeceiras" urbanas, pelo que não foram contabilizados no 
censo. Por outro lado, a natureza do evento de deslocamento envolve muito mais do que uma mudança de residência e, de fato, um deslocado forçado pode ter sido deslocado mais de uma vez, o que também escapa à fonte censitária, mas não ao sistema de registro contínuo. Dada a situação de vulnerabilidade e medo que envolve a condição de deslocado, não se descarta que no momento do censo possa ter omitido informação, afetando também a numeração de migrantes forçados.

A partir das duas fontes, porém, é possível verificar dois aspectos relevantes do comportamento dos movimentos forçados. Em primeiro lugar, as duas fontes confirmam que mais de $95 \%$ dos municípios experimentaram eventos de expulsão forçada. E em segundo lugar, que existem regiões onde a incidência da expulsão foi mais intensa, o que coincide nas duas fontes.

Segundo o conceito de migração, que considera como migrantes aqueles que mudam de residência, mas que tenham cruzado limites político-administrativos, o Censo 2005 não mede os possíveis deslocados forçados que mudaram de residência dentro do mesmo município. Isto faz com que o volume da migração forçada seja consideravelmente inferior ao volume de deslocados que registra a fonte oficial RUPD-RNI.

Quando um deslocado forçado se encontra coagido a sair da sua residência e procurar outro destino além dos limites nacionais, pesa fundamentalmente o temor de não receber suficientes garantias para a preservação da sua vida. Este é, de fato, um dos elementos sobre o qual se constrói o conceito atual de refugiado (ONU, 1956). Desde 1980 até o ano 2012, a Agência das Nações Unidas para os Refugiados apresentava um registro de 2.313.884 de refugiados procedentes da Colômbia ${ }^{6}$. Observe-se que as tendências do número de deslocados e de refugiados são similares (Gráfico 1), o que é de se esperar, já que um refugiado internacional tem sido previamente um deslocado forçado. A diferença, porém, está em que não necessariamente todo refugiado internacional foi contabilizado previamente como deslocado forçado.

O que é possível identificar são os destinos internacionais. Do total de refugiados internacionais entre 2000 e 2012, que somam 2.198.541, os principais destinos foram a Venezuela, com $46 \%$, e o Equador com 28,7\%. Estes dois países abrigaram durante este período $75 \%$ dos refugiados de origem colombiana, quer dizer 1.642.615. Em ordem de importância se encontram Estados Unidos $(8,6)$, Costa Rica $(4,16)$, Canadá $(5,4)$ e Panamá $(3,9)$, para um total de 485.128 refugiados (ACNUR, 2014).

\footnotetext{
${ }^{6}$ Cabe mencionar que existem migrantes internacionais em condição forçada que não são reconhecidos como tal, na medida em que algumas solicitações de asilo são rejeitadas nos países de destino. Existem outros casos em que os migrantes internacionais em condição forçada preferem não solicitar o asilo nem adquirir a condição de refúgio para não perder o direito de votar no país de destino nem no país de origem.
} 


\section{Gráfico 1. Deslocados forçados e refugiados internacionais da Colômbia.}

Série 1980 a 2001

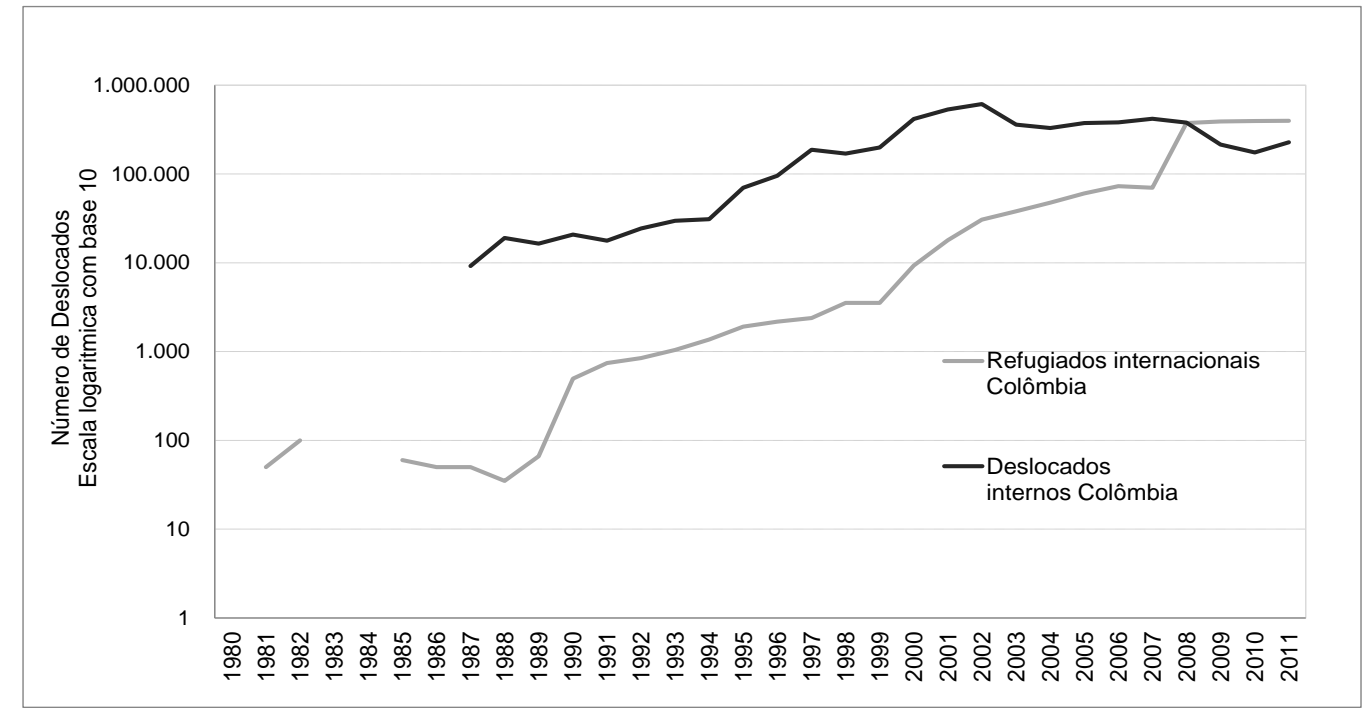

Fonte de dados: ACNUR (Mundo), A Colômbia (RNI).

A participação na cobertura dos refugiados diminui na medida em que as distâncias geográficas aumentam. Um terceiro grupo de países de asilo corresponde a países da Europa, como o Reino Unido, a Espanha e Suécia que, conjuntamente, abrigaram 25.851 colombianos. Entre os outros países da América Latina, os destinos principais foram Chile $(0,29 \%)$, Brasil $(0,21)$ com 6.338 e 4.721 , respectivamente. Cifras que percentualmente parecem insignificantes, mas que em termos absolutos não deixam de ser alarmantes.

Contudo, o amplo volume da migração interna entre 1988 e 1993, a sua diminuição entre 2000 e 2005, e o recíproco aumento da migração internacional, refletem fundamentalmente a extensão e o aprofundamento dos fatores de expulsão. As áreas rurais perderam população em valores absolutos, e o crescimento da população colombiana como um todo se desacelerou, tendências envolvidas com o comportamento da migração rural-urbana e com a migração internacional, respectivamente.

\section{Conclusões}

O processo de desindustrialização em Colômbia, desde a década de 1980, aunado à instauração da política de abertura econômica durante os anos 1990 para a qual o país não estava estruturado, parecem ter contribuído na diminuição da capacidade do aparto produtivos para articular a população ativa ao mercado de trabalho nas áreas urbanas influenciando, por tanto, os movimentos migratórios internos e incentivando as emigrações internacionais.

Concomitantemente, a desestabilidade social e econômica derivada do conflito armado, sustentado na economia do narcotráfico e nas ações violentas de todos os grupos envolvidos 
nas áreas rurais, que já arrastava sua inércia desde a década de 50, exacerbou a expulsão de milhares de camponeses em condições forçadas para dentro e fora dos limites nacionais em finais dos 90 e durante toda a década de 2000.

A configuração histórica de complexos de fatores de expulsão, de ordem econômico e político na transição ao século XXI, conduziu o país a uma situação de crise, que se revela na exacerbação dos movimentos migratórios dos colombianos, que de fato, não se circunscrevem espacialmente às fronteiras internas, nem se restringem aos limites conceituais da definição de migração. Nesse comportamento se misturam, superpõem, articulam e configuram diferentes modalidades de movimentos, originados por causas de naturezas diversas, não determinantemente ou exclusivamente voluntárias ou forçadas.

De modo que em um primeiro balanço do padrão de mobilidade, para o começo da década de 1990 e de 2000, observa-se fundamentalmente a diminuição do volume da migração interna de caráter voluntário e, em contrapartida, o aumento dos deslocamentos de caráter forçado, internos e internacionais, mas que não são captados nos censos demográficos.

Os resultados da análise fornecem elementos para afirmar que a fragmentação dos estudos das migrações em termos conceituais e espaciais restringe a possibilidade de compreender os processos migratórios como um todo. No caso da Colômbia, particularmente, essa restrição impede dimensionar as implicações do conflito armado aquém e além dos limites. 


\section{Bibliografia}

ACNUR. (2015, Mayo 25). Tendencias Globales sobre refugiados y otras personas de interés del ACNUR. Retrieved from http://www.acnur.org/t3/recursos/estadisticas/

BUSHNELL, D. (2007). Colombia, una nación a pesar de sí misma. Nuestra história desde los tiempos precolombinos hasta hoy. (C. M. V., Trans.) Bogotá: Planeta.

CARVALHO, J. A., \& RANGEL RIGOTTI, J. I. (1998). Os dados censitários brasileiros sobre migrações internas: algumas sugestões para a análise. XI Encontro Nacional de Estudos Populacionais da ABEP, 339 - 356.

CASTLES, S. (2003). Towards a sociology of forced migration and social transformation. Sociology, $37(1), 13-34$.

CASTLES, S. (2008). Development and Migration - Migration and Development: What comes first? International Migration Institute. Oxford University, 18.

CASTLES, S., \& MLLER, M. $(1993,1998)$. The age of migration. International population movements in the modern world. New York: The Guilford Press.

CUERVO, S. (2014). Migração interna e deslocamento forçado: Análise do padrão migratório colombiano do final do século XX e começo do século XXI. Tese de Doutorado em Demografía, Universidade Federal de Minas Gerais, Programa de Posgraduação em Demografía. Faculdade de Ciências Económicas., Belo Horizonte - Brasil.

DANE. (1996). XVI Censo Nacional de Población y de Vivienda. Bogotá: DANE.

DANE. (2003). Evidencia reciente del comportamiento de la migración interna en Colombia a partir de la Encuesta Continua de Hogares. Dirección de Metodología y Producción Estadística. Bogotá: DANE.

DANE. (2008). Censo general 2005. Nivel Nacional. Bogotá: DANE.

de HAAS, H. (2006). SISTEMAS MIGRATORIOS EN EL NORTE DE ÁFRICA: EVOLUCIÓN, TRANSFORMACIONES Y VÍNCULOS CON EL DESARROLLO. Migración y Desarrollo, 63 - 92.

De HAAS, H. (2010). Migration and development: a theoretical perspective. International Migration Institute. University of Oxford, 41.

FAJARDO, D. (2009). Territorios de la agricultura colombiana. Bogotá, Colombia: Centro de Investigación sobre Dinámica Social CIDS - Universidad Externado de Colombia.

KALMANOVITZ, S., \& LÓPEZ, E. (2006). La agricultura colombiana en el siglo XX (Primera edición ed.). Bogotá, Colombia: Fondo de Cultura Económica.

KALMANOVITZ, S., \& LÓPEZ, E. (2007). Aspectos de la agricultura colombiana en el siglo XX. In Economia Colombiana en el Siglo XX. Un análisis cuantitativo. (pp. 127 - 168). Bogotá: Banco de la República y Fondo de Cultura Económica. 
Ley de Vitimas 1448. (2011). Ley de vícitmas y restitución de tierras. Bogotá - Colombia: Presidencia de la República de Colombia Agencia Presidencial para la Acción Social y la Cooperación Internacional - ACCIÓN SOCIAL.

LUCAS, R. (1997). Internal Migration in developing countries. In M. Rozenweig, \& O. Stark (Eds.), Handbook of Population and Family (pp. 721 - 798). Amsterdam: Elsevier.

MASSEY, D., ARANGO, J., GRAEME, H., KOUAOUCl, A., PELLEGRINO, A., \& TAYLOR, E. (1993). Theories of International Migration: A review and and appraisal. Population and Development Review, 19(3), 431 - 466.

MASSEY, D., ARANGO, J., GRAEME, H., KOUAOUCI, A., PELLEGRINO, A., \& TAYLOR, E. (1998). Worlds in motion. Understanding Internacional Migration at the End of the Millennium. New York: CLARENDON PRESS - OXFORD.

ONU. (1970). Manuals on methods of estimating population. Manual VI. Methods of Measuring Internal Migration. New York: Department of Economic and Social Affairs. Population Studies, No 47.

PALACIOS, M., \& SAFFORD, F. (2002). Colombia país fragmentado, sociedad dividida. Su historia (Primera ed.). (P. Marco, \& G. Ángela, Trans.) Bogotá: Norma.

PÉCAUT, D. (1987, Marzo). Acerca de la violencia de los años cincuenta. Boletin Socioeconômico CIDSE de la Universidad del Valle(17).

PÉCAUT, D. (2013). La experiencia de la violencia: Los desafios del relato y la memoria (Primera Edición ed.). Medellín: La Carreta Editores.

RNI. (2015, Mayo 25 ). Red Nacional de Información. Unidad para la atención integral a las víctimas . Retrieved from http://rni.unidadvictimas.gov.co/?q=node/107.

RODRIGUEZ Vignoli, J., \& BUSSO, G. (2009). Migración interna y desarrollo en América Latina. Un estudio comparativo con perspectiva regional basado en siete países. (1 ed.). Santiago de Chile: ONU - CEPAL.

RONDEROS, M. T. (2014). Guerras recicladas. Una historia periodística del paramilitarismo en Colombia. Bogotá: Aguilar.

VILLA, L., \& ESGUERRA, P. (2007). El comercio exterior colombiano en el siglo XX. In Economía Colombiana en el Siglo XX. Un análisis ciantitativo (pp. 81 - 124). Bogotá: Banco de la República y Fondo de Cultura Económica.

WALLERSTEIN, I. (1974). The modern world-system. New York: Academic.

WHITOL DE WENDEN, C. (2013). El fenómeno migratório en el siglo XXI. Migrantes refugiados y relaciones internacionales (Primera edición en español, 2013 ed.). México: Fondo de Cultura Económica.

ZELINSKY, W. (1971). The hipothesis of the mobility transition. Geographical Review(61), 219 - 249.

ZOLBERG, A., SUHRKE, A., \& AGUAYO, S. (1989). Escape from violence. Conflict and the Refugee Crisis in the Developing World. New York Oxford: OXFORF UNIVERSITY PRESS. 